\title{
Title:
}

\section{With love, from me to you: Embedding social interactions in affective neuroscience}

\section{Authors:}

\author{
Gadi Gilam ${ }^{1,2 *}$, Talma Hendler ${ }^{1,2,3,4 *}$
}

\author{
Affiliations: \\ ${ }^{1}$ Tel Aviv Center for Brain Functions, Wohl Institute for Advanced Imaging, Tel Aviv Sourasky \\ Medical Center, Weizmann 6, Tel Aviv, 64239, Israel \\ ${ }^{2}$ School of Psychological Sciences, Tel-Aviv University, P.O. Box 39040, Tel Aviv 69978, Israel \\ ${ }^{3}$ Faculty of Medicine, Tel-Aviv University, P.O. Box 39040, Tel Aviv 69978, Israel \\ ${ }^{4}$ Sagol School of Neuroscience, Tel-Aviv University, P.O. Box 39040, Tel Aviv 69978, Israel
}

*Correspondence: gadi.gilam@gmail.com; talma@tlvmc.gov.il;

Tel Aviv Center for Brain Functions, Wohl Institute for Advanced Imaging, Tel Aviv Sourasky Medical Center, Weizmann 6, Tel Aviv, 64239, Israel.

Tel.: +972 (0)3 6973549

Fax: +972(0)36973080

\begin{abstract}
$\underline{\text { Abstract }}$
Human emotional experiences naturally occur while interacting in a spontaneous, dynamic and response contingent fashion with other humans. This resonates with both theoretical considerations as well as neuroimaging findings that illustrate the nexus between the "social" and "emotional" brain suggesting a domain-general organization of the brain. Nevertheless, most knowledge in affective neuroscience stems from studying the brain in isolation from its natural social environment. Whether social interactions are constitutive or not to the understanding of other people's intentions, incorporating such interactions is clearly required for ecological validity. Moreover, since interpersonal interactions may influence emotional experiences and expressions,
\end{abstract}


interactive paradigms may advance the theoretical understanding of what emotions are and what about them is social, and will correspondingly characterize their underlying neural substrates. We highlight the recent conceptual and experimental advances of bringing realistic social interactions into the neuroimaging lab; review emotion-induction paradigms and consider their congruency with features of social interactions; and emphasize the importance of embedding such spontaneous and dynamic interactive paradigms in the field of affective neuroscience.

\section{$\underline{\text { Keywords }}$}

Emotion; Social emotion; Interpersonal relations; Social neuroscience; Self; Ecological validity; Domain-general; Games; Neuroimaging; fMRI 


\section{Introduction}

Just as an artificially imitated sneeze lacks something of the reality, so the attempt to imitate an emotion in the absence of its normal instigating cause is apt to be rather "hollow". (James, 1884, p. 192)

How often do we find ourselves running away in fear from a bear or beating angrily at a snake? Presumably, it is more likely to happen if we lived in a cave near the forest, but when was that? Nowadays most humans live in cities, drive cars to get to work and shop in supermarkets for food. It is therefore quite natural that emotional episodes occur mostly during our interactions with other people in our environment - family members, friends and colleagues, and even complete strangers stumbled upon our daily routines (Fischer and van Kleef, 2010; Scherer et al., 2004; Scherer and Tannenbaum, 1986). Indeed, social life is suggested to be the force behind, and in itself at the peak of the evolutionary development of human brain and intelligence (Byrne and Whiten, 1989;

Dunbar, 2003, 1998; Whiten and Byrne, 1997). Is it possible that this evolutionary force influenced our lives to such a degree, but somehow left our emotional repertoires as basic survival responses (Panksepp, 1998)? Perhaps; but at the same time, at least as far as ecological validity is concerned, can we assume that people laying inside the MRI scanner feel the same when shown an emotional picture or face, when recalling or imaging an emotional situation, or when actually being provoked by another person?

Most studies in affective neuroscience use several types of well controlled stimuli to elicit emotional experiences (see Lench and colleagues (2011) for a general review outside the realm of neuroscience). The classic use of pictures from the International Affective Picture System (Bradley and Lang, 2007) or of standard facial expressions (e.g. Fusar-Poli et al., 2009) enables high standardization across and within subjects, yet these are static stimuli, typically presented for brief periods of time and usually having a low impact on participants as far as psychological realism. Self generation of emotions by recollecting personal autobiographic experiences might offer more 
personalized reverberations of emotional episodes, such as death of a close person or causing harm to another person (e.g. Damasio et al., 2000; Wagner et al., 2011), yet these experiences might be contextually different across subjects and also, since the experience has already been processed, may be prone to confounds of memory-biases or limited introspective insight. One possibility to overcome these problems is to ask participants to read sentences or short paragraphs, or observe pictorial vignettes depicting emotional contents (e.g. Burnett et al., 2009; Krach et al., 2011), or better yet, to use specifically scripted imagery of such events (e.g. Frewen et al., 2011; WilsonMendenhall et al., 2013). However, such stimuli lack the dynamic feature of emotions, a critical feature that has been relatively absent from empirical inquiry (Frijda, 2009), especially when considering the important role of dynamics in social interaction. Using film-clips is a very good option that combines the benefits of a standardized stimulus with the ability to dynamically experience and regulate emotions (Raz et al., 2012). And yet, while viewers may witness the interactions of others in the movie-clips, the viewers themselves aren't necessarily the direct target of emotional provocations and in any case are in a passive state. These standard paradigms do not capture the interactive nature of emotions as dynamically experienced in our daily lives (Table 1A) and in the case of anger, for example, such different paradigms evoke differential neural processing (Gilam and Hendler, 2015). While an effort to embed social interactions is clearly required for improved social realism and generalizability in affective neuroscience, we believe for several reasons detailed in the next section that such naturalistic paradigms also hold promise for a theoretical advancement of our understanding of emotional experiences and their underlying neural substrates.

\section{$\underline{\text { 2. A theoretical consideration of the effects of social interactions on emotions }}$}

When William James asked in his seminal paper "what is an emotion?" he clearly recognized the basic sociality of human emotional life, yet he framed it as an emotional percept as any, without 
considering the possible role of social interactions within the emotional experience (1884, p.195-

196):

A nervous tendency to discharge being once there, all sorts of unforeseen things may pull the trigger and let loose the [emotional] effects. That among these things should be conventionalities of man's contriving is a matter of no psychological consequence whatever. The most important part of my environment is my fellow-man. The consciousness of his attitude towards me is the perception that normally unlocks most of my shames and indignations and fears. The extraordinary sensitiveness of this consciousness is shown by the bodily modifications wrought in us by the awareness that our fellow-man is noticing us at all. No one can walk across the platform at a public meeting with just the same muscular innervation he uses to walk across his room at home. No one can give a message to such a meeting without organic excitement. (...) [but] What the [emotion inducing] action itself may be is quite insignificant, so long as I can perceive in it intent or animus. That is the emotion-arousing perception (italics in original).

James seemed to argue that people themselves are not essentially different than other percepts as triggers of emotional experiences. However, when we interact with other people in our environment we are not mere passive observers; we are able to spontaneously convey our thoughts, feelings and intended actions towards those people and in response to their own thoughts, feelings and actions, thus adapting our behaviors and cognitions within the unique dynamics of the situation. These dynamic interactions may alter how we perceive the intentions of other people and thus may influence the emotional episode, especially if the interactions themselves may hold unique information constitutive to how we understand other people (e.g. De Jaegher et al., 2010; Di Paolo and De Jaegher, 2012). For example, when someone bumps into you while walking down the street, both of you stumble and almost fall and you might think she did that on purpose and that she is directly responsible for you getting hurt. But she might immediately apologize and explain that she had a sudden loss of balance or she might be angry for hurting you because someone else pushed her. Certain information may come to light vis-á-vis the interaction which alters how you 
understand the sequence of events and may direct attention away from "what she did" and "how I feel" to focus on the momentary interdependency between you two.

In light of this notion it is important to consider, as suggested in the influential work of sociologist Ervin Goffman (1959), that during social interactions people are mutually aware of being engaged with and by another person and thus may alter how they present themselves to influence and monitor the kind of impression that is being formed of them. This dynamic process occurs reciprocally between both sides of the interaction which like actors performing on stage disclose certain information about their character or self to the audience, while concealing other. Each individual is thus both an actor and an audience within the interaction. The emphasis on the self and how it is presented and perceived may lead to a loop in which each persons' self attempts to present itself in accordance with the way it might be perceived by others. In this sense the self is not only an actor but may also be a product of the interaction ${ }^{1}$. This conceptual role of the self in social interactions may influence and induce a whole range of dynamic emotional experiences and displays. One can be (present her self as) hurt and insulted to create the impression of a breach of social conduct and therefore legitimize their anger. One may also be embarrassed at not being able to maintain the desired impression of her self ${ }^{2}$.

From a contemporary neuroscientific perspective, Antonio Damasio (2010) proposed a structured psychological account of the self based on neural assumptions. At its most basic level the self consists of a protoself which its' most distinct feature is its basic role in generating primordial feelings by nuclei localized in the brainstem, such as the parabrachial nucleus (PBN) and the periaqueductal gray (PAG). These nuclei have an important role in sensing the internal milieu of the body and conveying this interoceptive or embodied information to cortical regions such as the insula. These basic feelings ranging from pleasure to pain reside at the core of more complex

\footnotetext{
${ }^{1}$ While Goffman focused on the self as an actor within the social interaction, his work is based on the theoretical framework of George H. Mead (1934) who emphasized the self as a social product, though functionally differentiating between an acting self ('I") and a socialized self ("me").

${ }^{2}$ For a prominent psychological analysis on the socialization of emotions via the integration of self and culture one may consider Markus and Kitayama (1991).
} 
emotional experiences such as being happy or angry ${ }^{3}$. In a possible merger between Damasio and Goffman, primordial feelings and emotions are building blocks of the self and therefore may be dramatized during social interactions.

Following up with Damasio (2010), once the protoself engages with an external event or object, the next level of the self emerges, the core self, which generates saliency or attention to that event by other nuclei of the brainstem including those of the reticular formation, the monoaminergic nuclei and the cholinergic nuclei. In a recent realistic and interactive induction of anger (elaborated in more detail in section five) we showed the involvement of the Locus Coeruleus (LC), a monoaminergic (noradrenergic; NA) nucleus in charge of regulating autonomic arousal, as well as other brain regions including those involved in interoceptive processing, in mediating the experience and expression of anger (Gilam et al, 2015). To our knowledge this is the first neuroimaging evidence highlighting the association between LC and anger, possibly because anger was induced during dynamic social interactions. Interestingly, it has been suggested that within its role in reorienting attention to salient events, the LC-NA system is also involved in driving attention to the intentions of other people as evidenced by the neural interaction between this system and regions involved in understanding other people, such as the temporal-parietal junction (TPJ) and extending towards the posterior cingualte cortex (PCC)/precuneus (Corbetta et al., 2008). Notably these same regions encompass Damasio's autobiographical self "whose higher reaches embrace all aspects of one's social persona" (2010, p. 23).

In addition to the above postulations regarding the possible influence of social interactions on humans' emotional experiences, the nature of the relationship to the person with which we interact (friend or foe; familiar or stranger), the goal of the interaction (cooperative/competitive/incidental) as well as the possibility of past or future interactions, are all important factors that may influence

\footnotetext{
${ }^{3}$ For simplicity and focus, we do not make here an explicit distinction between affect and emotion, the former commonly considered as an umbrella term encompassing any psychological state that is felt and valenced, including emotions, emotional states, moods, pains and pleasures. Russell and Barrett (1999) provided an important definition and distinction between core affect and a prototypical emotional episode in similarity to Damsio's (2010) primordial feelings and emotions, respectively. Kober and colleagues (2008) illustrate that some brain structures involved in core affect overlap with those involved in primordial feelings, such as the PAG.
} 
peoples' emotional reactions to one another, which in turn may themselves alter the status of the relationship and the course of interaction (Fischer and van Kleef, 2010). Similarly, the information communicated during social interactions does not sum up to what people say or do but also to how and in what way do they say or do it and the kind of gestures or body language they use to convey their intentions. In their conception of an interactive "second-person neuroscience", Schilbach and colleagues (2013) suggested that emotional responses to a person with which one interacts with can also be influenced by one's own and the other person's somatic state. Consequently, emotional and embodied networks in the brain may interact and facilitate ways of understanding the internal state of that person, subsequently leading to an emotional response towards her. While resonating with the ideas illustrated above and suggesting that when interacting with another person the self is directly engaged via an emotional response to that other, this mechanism may occur also when merely observing an emotionally charged scene. We have demonstrated that a measure corresponding to the cohesiveness between emotional and embodied networks when viewing a sad movie correlated with a self reported measure of sadness towards that movie (Raz et al., 2014). Moreover, a recent effort to study interpersonal emotions such as embarrassment in a realistic socially immersive situation (elaborated in more detail in section five) provided evidence of information transfer between brain regions involved in understanding other people's intentions, in emotional reactions and in interoception (Müller-Pinzler et al., 2015).

Emotions have an important role in shaping and motivating social interactions and as hypothesized here, the reverse similarly holds true - social interactions may fashion peoples' emotional experiences and expressions, and consequently their underlying neural manifestations. To date however, neuroscientific evidence regarding the experience and expression of emotions during truly interactive situations is still very limited. Therefore, a major concern for the empirical and theoretical progress of affective neuroscience is to reveal the neurobiological mechanisms that mediate emotional episodes during realistic interpersonal interactions. In the following we outline a possible framework for such a research perspective, beginning with a short theoretical overview 
suggesting that any emotional experience which may be influenced by social context and/or emerge during social interactions could be defined as a social emotion. We subsequently illustrate the overlap between the "social" and "emotional" brain supporting the notion that the brain is organized in domain-general components, though leaving as an open question whether interactive paradigms will similarly support such a notion or not. We next provide a definition of social interaction, considering the current theoretical debate as to their possible role in understanding other people and conclude with a review of studies that pushed the boundaries in "closing the loop" on social interactions in the field of affective neuroscience. Table 1 summarizes these studies noting their compatibility with various features of emotional episodes as with specific features of social interactions.

\section{What is a social emotion?}

There is much controversy as to what would be the answer to James' question, "What is an emotion?", let alone any consensus on how to define the term emotion (Russell, 2012). Though a comprehensive survey of the literature breaches the scope of this review and may be found elsewhere (Averill, 2012; Cunningham, 2013; Moors et al., 2013; Russell et al., 2011), in their historical account of the field Gendron and Barrett (2009) outline three main categories of theories of emotion. Basic emotion theories generally refer to a set of emotions such as anger, fear, surprise and happiness, as biologically ingrained and universally triggered by certain events or objects in the environment. Appraisal theories generally contend that emotions are the result of a meaningful interpretation that individuals assign to events or objects in their environment. Constructionist theories refer to emotions as constructed from the interplay between domain-general ingredients that are not specific to emotions per se. This approach is similar to appraisal in that an emotional episode involves an act of interpretation, but here the emphasis is on interpreting the internal state of the body as it is related to the situation, and not as appraisal theories suggest, an interpretation of the situation itself. 
All three theoretical perspectives on emotion incorporate a role for social factors, albeit different for each perspective. While appraisal and constructionist perspectives try to incorporate social factors in coping with the known variability in emotional responding across situations and cultures (Barrett, 2009; Frijda, 1986), basic emotion perspectives argue that social learning occurs as an ontogentic influence that is separate from the phylogentic nature of basic emotions, explaining the variability in emotional responding (Ekman and Cordaro, 2011). In fact, a basic emotion perspective does not necessarily distinguish between basic and social emotions, rather between emotions and other mental states. Interestingly, emotions such as guilt or envy are on the verge of being regarded as basic emotions, but there is need of further cross-cultural evidence. From a completely different perspective, social constructivists may similarly argue for no difference between basic and social emotions, but that is because every emotion is supposedly subject to the engineering of social influences (Averill, 2012; Rogers et al., 2014).

There are additional more specific definitions of what may constitute a "social emotion". According to the Stereotype Content Model (Fiske et al., 2002), encounters with representatives of different out-groups may evoke specific emotions such as disgust, pity, pride and envy. Inspired by this model, Harris and Fiske (2006) defined exclusively social emotions ${ }^{4}$ as those which occur only in the presence of other people and give the example of envy, which can be felt towards the owner of a sports car but not towards the car itself, as compared to disgust which can be felt towards both a person and an object. Nevertheless, it seems that we do not actually need the presence of another person rather we may just need to have the representation of another person's mental state (i.e., mentalizing/theory of mind). In line with this notion, Burnett and colleagues (2009) defined social emotions as those emotions that require mentalizing about other people and give the example of embarrassment, which one may feel only when representing someone else's negative evaluation of oneself (Miller, 1995). Indeed, basic emotions do not necessitate mentalization, such as fear in the startle effect, yet this does not mean that such emotions do not rely on it. For example, an

\footnotetext{
${ }^{4}$ Some have used a less stringent definition of social emotions as those that occur in the presence of others, not necessarily exclusively (Britton et al., 2006).
} 
adolescent who is fearful of her parents' reactions after wrecking their car must have a

representation of their mental state. On the other hand, a form of embarrassment related to the mere exposure to public attention has been claimed to exist as early as 2-years of age (Lewis, 1995;

Lewis et al., 1989) around which infants have already developed a rudimentary concept of the self as distinguished from others but still lack mentalization skills that emerge at a later stage (Brüne and Brüne-Cohrs, 2006). This may suggest that a social emotion necessitates self-awareness (Tangney and Fischer, 1995; Tracy and Robins, 2004). Such self-conscious emotions such as "shame" and "guilt" have also been termed moral emotions (Eisenberg, 2000). Notably however, there is evidence that neonates and toddlers void of any differentiation between self and others, let alone of the effects of social learning or mentalizing capabilities, can experience a primitive form of emotional contagion - an automatic resonance with socially transmitted emotional states (Hatfield et al., 1994). This does not mean that moral emotions do not require a self/other distinction rather that an emotional or affective ${ }^{5}$ state could be mediated by emotional contagion from other agents in the environment and thus provide another possible definition of what would make an emotion social. This rudimentary form of emotional sharing between individuals is considered one of the building blocks of the human capability to empathize. Empathy in itself has been subject to many different definitions (Batson, 2009), some of which regard it as an emotional state per-se, dependent upon the emotional state of another person, while others refer to empathy as a process that enables to understand and even experience the emotional states of others. It is therefore clear that there is no consensus as to what defines an emotion as social and an in depth theoretical consideration can be found elsewhere (Hareli and Parkinson, 2008; Parrott, 2001). We propose to shift the discourse and instead of asking whether a specific type of emotion is social or not, or whether a social emotion is in itself a type of emotion, embrace (as previously suggested by Lamm and Singer, 2010) a broad

${ }^{5}$ Hatfield and colleagues (1994) do not make a clear and explicit distinction between affect and emotion and throughout their work present evidence for both being influenced by emotional contagion, for example (p. 84): "a toddler who buries his face in his mother's lap upon seeing another child fall and cry, or who strikes his doctor in anger when he sees another child receiving an injection." 
perspective which views any emotional episode as social if it is somehow influenced by social context and/or if it might arise during social interactions.

\section{Social-Emotional overlap in the brain}

In reverberation of the theoretical debate as to the inherent sociality of emotions, the nexus between social-cognition and emotion has been acknowledged and demonstrated in the modern era of neuroscience by showing that brain regions that were associated with processing emotions were also associated with social-cognition (Adolphs, 2009, 2003; Barrett and Satpute, 2013). The amygdala, for example, has been considered as the core region of the "emotional brain" for many years (e.g. LeDoux, 1992), but at the same time has also been suggested to play a primary role in the so-called "social brain" (Brothers, 1990). Another example stems from findings that ascribe a role to the anterior Insula (aI) in processing subjective feelings but also when empathizing with others (Singer et al., 2009).

These kind of overlapping findings have contributed to the shift from a locationist approach, in which complex function is assumed to be consistently and specifically processed in discrete brain regions, to a network-based approach that conceptualizes function as emerging from dynamic interactions between and/or within distributed brain regions (Bressler and Menon, 2010; Lindquist and Barrett, 2012). This approach has been advanced also by the "resting-state" paradigm which reveals intrinsic functional brain-networks when no external stimulus or task is present; networks that are suggested to be related to the underlying anatomical connectivity and thus also to functional performance (Deco and Corbetta, 2011; Raichle, 2010). However, in a recent review it was noted that the overlap between different functions and similar brain regions is also apparent when considering a network-based approach (Barrett and Satpute, 2013). For example, the so called "default mode" network, so named because of its' consistent appearance whenever people are not actively engaged in a goal directed task, possibly letting their minds wonder (Gruberger et al., 2011), has also been consistently engaged during tasks requiring social-cognition, especially when 
attributing mental states to others and has thus also been termed the "mentalizing"/"theory of mind" network (Mars et al., 2012; Schilbach et al., 2008). Moreover, the main brain regions of this network, the medial prefrontal cortex (mPFC) and the PCC/precuneus, have also been shown to be engaged during various emotional states (Kober et al., 2008; Lindquist et al., 2012). In fact a metaanalysis converging on resting-state, social-cognition and emotion studies has shown that these two regions are the only ones to have direct statistical overlap in all three domains (Schilbach et al., 2012). Moreover, we have shown that the mentalizing network has a role in mediating between a vicarious emotional experience and one's own emotional experience (Raz et al., 2014), providing a possible explanation for the overlap of this network in various social-emotional contexts.

All these observations are in line with the notion that the brain is not organized according to preprogrammed definitions of what is social or emotional. In other words, the brain does not seem to contain specific modules for processing only social or only emotional stimuli but rather is organized in more domain-general modules that have important functionalities for processing both emotional and social information. To provide coarse support for this idea, we used NeuroSynth (Yarkoni et al., 2011) - a web-based platform for large-scale automated meta-analyses of fMRI data - to examine the overlap between meta-analytic maps of social and emotional studies (Figure 1). We found extended and bi-laterally symmetrical overlap across the entire brain, including the amygdala, thalamus, various regions of the fusiform gyrus, middle temporal lobe, basal ganglia including the caudate, nucleus accumbens and putamen, inferior frontal gyrus (IFG) extending towards the insula (especially its anterior aspect), lateral and dorso-lateral PFC, mPFC (extending from orbito-ventral towards dorsal regions), anterior cingulate cortex, $\mathrm{PCC}$, precuneus, supplementary motor cortex (SMA) and motor and parietal activations, including the TPJ. Even when removing a large subset of studies (314 in number) that were initially included in both the social (1000 studies) and emotional (1340 studies) meta-analytic maps, the overlap in these brain regions hardly changed. It is important to highlight that these meta-analytic maps are rough estimations and possibly provide an over generalization as we did not differentiate between various factors such as healthy and patient 
populations or between paradigms and induction methods. Future endeavors of more rigorous and precise meta-analytic efforts would be beneficial for the field. Notwithstanding, all studies included in these meta-analytic maps as well as the vast majority of findings on the neurobiological underpinning of human social and emotional life are based on "offline" controlled laboratory paradigms during which participants' brains are studied in isolation from other agents in the environment. Could social interactions be the key for a clear dissection between the "social" and "emotional" brain? Will it further emphasize the inherent sociality of human emotions? Will we find a unique neural signature for emotions experienced during social interactions? At this point we do not have any evidence to suggest that embedding realistic social interactions will refute domaingenerality in neural processing but this should be scientifically scrutinized.

In recent years a growing number of researchers have addressed this problem and emphasized the need for the neuroscientific endeavor to study brain function in its naturalistic, socially interactive, "on-line" mode (Becchio et al., 2010; Hari et al., 2015; Hari and Kujala, 2009; Hasson and Honey, 2012; Schilbach et al., 2013; Zaki and Ochsner, 2009). In fact, a report from a National Science Foundation workshop on mapping and engineering the brain has identified neuroimaging in interactive and naturalistic environments as one of three grand challenges in mapping the human brain (He et al., 2013). At the same time a Frontiers Research Topic (Pfeiffer et al., 2013) has brought together over 50 contributions addressing this issue from multiple perspectives and just recently a special themed issue of the Philosophical Transactions of the Royal Society (Hari et al., 2016) added 15 more contributions, all attempting to shed some light on what has been termed the "dark matter" of social neuroscience.

\section{The matter of social interaction}

Social interaction has been defined as a social encounter involving at least two agents who reciprocally influence each other through verbal and/or non-verbal behaviors in a time dependent manner (De Jaegher et al., 2010; Di Paolo and De Jaegher, 2012; Schilbach et al., 2013). In 
addition, there seems to be a subjective element corresponding to a fluctuating perception or sensation of connectedness, ranging from none at all to possibly reflecting a unique sense of "we", which supposedly enables the agents to better understand each other. A more operationalized definition specifies four criteria for "closing the loop" on social interactions: dynamic interplay, unlimited range of responses, uncontrolled partners and emergent qualities (Przyrembel et al., 2012). However, there is an important theoretical debate as to whether the "we-ness" of social interaction indeed reflects an emergent property of the interaction that enables the agents to access additional information about one another or whether it simply reflects a first-person perspective that captures the self's engagement in social interaction (Gallotti and Frith, 2013). This later approach to social cognition, termed individualism, generally suggests that cognitive processing occurs in one's own mind and brain and that this is a precondition for understanding and interacting with others. Thus, the "we-mode" is achieved only when one can represent the others' perspective. The former approach, termed enactivism, generally suggests that social interaction is not merely a contextual effect but that it has a constitutive, though not the sole ${ }^{6}$, role in generating our capability to understand other people. In this sense, the dynamic co-dependent coupling between two or more agents may "take a life of its own" and in itself may shape the interacting individuals' cognition (De Jaegher et al., 2010; Di Paolo and De Jaegher, 2012). From this perspective, instances of copresence, the belief of the presence of another, or any other coupling which does not abide by dynamic co-dependency, are social and may have some level of interaction, but cannot be considered fully interactive.

In parallel to this theoretical debate, experimental advancement has brought research closer to full social interactions in domains such as joint action and joint attention. Eye-gazing tasks received considerable focus in relation to the neural substrates of social interaction (for reviews, see Risko et al., 2012; Schilbach, 2015), alluding to joint attention processes, which are considered developmental milestones in the human capability to communicate with others (Eilan, 2005). In one

\footnotetext{
${ }^{6}$ A stronger version of enactivism called interactionism holds that that social interaction has a constitutive and sole role in developing our understanding of other people
} 
of the first studies to explicitly focus on social interaction, Schilbach and colleagues (2006) used virtual reality to show that being personally involved in an eye-gazing interaction embedded with socially relevant cues activated the ventro-medial PFC (vmPFC). The next step in eye-gaze interactions was taken by using hyperscanning to investigate the joint attention of two participants who were required to follow each other's eye-gaze towards a target (Saito et al., 2010). In hyperscanning, two participants are simultaneously scanned in two separate MRIs while brain signals are acquired in synchrony with the behavioral interactions (Montague et al., 2002). Saito and colleagues (2010) devised a sophisticated setup in which each participant was provided with real-time video feed of the other participant's eye-gaze. Interactive gaze-following revealed higher inter-brain correlations in the right IFG in paired compared to non-paired participants. These studies suggest the brain regions in the prefrontal cortex might have a constitutive role in social interactions by integrating the shared intention of joint attention, though theoretical debate prevails (De Jaegher et al., 2016).

These examples however are important also from an experimental perspective because they point to the technological developments that are and will be imperative for developing social interactive paradigms in neuroscience (for reviews, see Babiloni and Astolfi, 2012; Bohil et al., 2011). The difficulty in designing such paradigms is determining where to draw the line between experimental control and real-world complexity. Joint-attention and joint-action tasks are highly controllable and provide an excellent starting point to study the building blocks of social interaction and coordination. However, creating a realistic situation in which participants can see, hear and talk to each other spontaneously, allowing engagement in interactive dynamics for the study of real-life situations is more challenging. By loosening the structure of the experiment one might gain generalizability but also increase the complexity of data analysis and the amount of possible artifacts and confounds, hindering the ability to draw conclusions. To cope with these issues neuroscientists must continue to be creative in designing new paradigms for new technologies, but should further aim for multilevel analysis (Cacioppo et al., 2013; Cacioppo and Berntson, 1992). 
That is, not only various neural signals such as fMRI and EEG to accompany behavioral measures, but also autonomic, hormonal and genetic measures, etcetera. Such multilevel experiments will allow for converging evidence that may negate alternative explanations and possibly compensate for diminished controllability. As illustrated above and in Table 1A, studies in affective neuroscience commonly use several types of well controlled stimuli to elicit emotional experiences. However, while using social interactions as a platform for emotional inductions is rare, neuroimaging studies focusing on social interactions have largely overlooked the importance of emotional experiences within such dynamics.

\section{Studies embedding features of social interactions}

There have been several studies with an affective flavor that managed to create interactive environments within the MRI scanner, many of which dealt with questions related to social/moral behavior and used different type of games (Table 1B). For example, to study social exclusion, Eisenberger and colleagues (2003) asked participants to play a virtual ball-tossing game (Cyberball) in which participants were led to believe that they were playing with two other participants in other MRI scanners. At a certain time point in the game the two confederate participants were preprogrammed to stop tossing the ball to the real participant excluding him or her from the game and leading to socio-emotional distress that correlated with activity in the dorsal anterior cingulate cortex (dACC), associated with the affective component of pain. Singer and colleagues (2004) related brain activity in the dACC and aI as part of an empathic response to pain inflicted to another person seated adjacent to the participants inside the MRI scanner. In a subsequent study they showed how this empathic response to pain was modulated by the type of interaction participants had with two other people that preceded the painful stimulation (Singer et al., 2006). The interaction was based on an economic trust game with the two confederates, one of them preprogrammed to play fairly and the other unfairly. The empathic response was more apparent for the fair as compared to the unfair confederate, and more so amongst women as compared to men. However, 
men showed increased activity in the Striatum, a reward-related brain region, during pain infliction to the unfair confederate, which positively correlated with their desire for revenge. In other words, it seems that this reward-related signal represents the satisfaction from punishment inflicted upon an unfair player. Similar results were shown in a positron emission tomography (PET) study, in which participants played an economic trust game and the amount of money they were willing to invest in punishing an unfair player scaled with activity in the Striatum (de Quervain et al., 2004). In these studies creating interactive games and even bringing other people into the scanner environment increased realism but there was no interaction during the actual measurement of brain activity.

An important field of research that commonly creates interactive environments via different types of games is decision making, which is further fused with theoretical models from game-theory and behavioral economics (Camerer, 2003; Sanfey, 2007). We created an interactive risk game allegedly played against the experimenter, in which participants had to get rid of all their domino chips to win the game (Kahn et al., 2002). The game was programmed to force participants to make risky choices in which they had to bluff to get rid of all their chips. If the bluff was exposed, they would be punished by receiving extra domino chips and thus their probability of wining was hindered. Such bluffs seem to capture naturalistic risk taking, regarded as exposure to possible loss or harm, rather than the standard economic definitions of risk as the variance of possible monetary outcomes (as suggested by Schonberg et al., 2011). The bluffs were associated with increased amygdala activation and increased skin-conductance response, together representing a possible suspenseful or anxious state while taking the risk. In an additional study using this game (Assaf et al., 2009), participants reported feeling glad when their bluffs were not revealed, but not distressed when they were, and this did not seem to change when playing against a computer instead of a human competitor. However there were activation differences in regions associated with the mentalizing network, including mPFC and TPJ, dependant on whether the game was played against a human or computer and whether the opponent exposed the bluff or not. It is thus possible that the anticipatory affective response when playing a bluff was related to hope for gain rather than fear of 
loss. But more importantly, while there were mentalizing-related differences when believing the game was played against a human compared to knowing it was a computer, it seems unclear whether the affective experience itself was modulated by this difference.

A possible reflection of affective differences between playing with a person compared to a computer was provided by the first fMRI study on the classic Ultimatum Game (UG; Sanfey et al., 2003). In the UG (Güth et al., 1982), two players need to agree on how to share a sum of money between them in order for them to gain that money. The first player decides how to split the sum of money while the second player decides whether to accept or reject the offer. If the offer is accepted both receive the designated amount of money, but if rejected both receive nothing. From the second players' perspective, game theory predicts acceptance of any offer larger than zero to maximize rewards, yet in most cases participants reject offers of about $25 \%$ and below of the total sum of money (Camerer, 2003). The common explanation is that these are regarded as unfair offers that elicit anger and thus result in retribution at one's own personal expense (Pillutla and Murnighan, 1996; Srivastava et al., 2009; Xiao and Houser, 2005). When participants lying in the scanner played several preprogrammed single-shot UGs of both fair and unfair monetary offers, increased aI, ACC and dorso-lateral PFC (dlPFC) activations were apparent for unfair compared to fair offers, but only for offers from supposedly real competitors and not from those randomly generated by a computer. Though anger was not directly measured, the negative experience inflicted to one's self could have mapped to the ACC which was previously associated with the affective component of pain. Interestingly, the aI and dlPFC showed a reverse pattern of activation such that unfair rejected offers had more aI activity compared to dIPFC, but unfair accepted offers had the reverse pattern of activation. In view of the insula's involvement in subjective feelings and dIPFC's involvement in cognitive control (Buhle et al., 2014; Miller and Cohen, 2001), this might coincide with a process of emotion regulation in which dlPFC asserts control over the aI to overcome the negative emotional response. Nevertheless, the contrast human vs. computer is not a one-by-one analogue to the contrast interactive vs. non-interactive. 
Although it is well known that emotions have an influence on decision-making (e.g. Lerner et al., 2015), in all the studies described, as in more social behavior focused studies, emotion was part of the story but was not the focus of the investigation - there was not a clear emotion elicitation or adequate inquiry of the emotional experiences of the participants, for example via extensive subjective ratings and/or psycho-physiological measurements. There were however several such efforts focusing on specific emotional experiences (Table 1C). In a study conducted in our lab, a game was designed to focus on the neural correlates of envy (a negative reaction to the fortune of others) and schadenfreude (a positive reaction to the misfortune of others; Dvash et al., 2010). Participants played a game of chance during which they chose a "fortune door" and received outcome feedback (monetary gain, loss or no change) whilst a confederate player supposedly in another scanner similarly chose a door and received outcome-feedback. Subsequently, participants saw their own results adjacent to that of the confederate's. Participants reported feeling envy when they won money but the other player won more money than them, and this correlated with decreased activations in the Striatum to a degree comparable to the actual loss of money. On the other hand, participants reported feeling schadenfreude when they lost money but the other player lost more money, and this correlated with increased activations in the Striatum to a degree comparable to the actual gain. While social comparison had a critical role in generating the emotional experience, there was no real dependency on the course of actions of another person, solely the co-presence of an "other".

Experimental games, especially those stemming from game-theory and behavioral economics, provide a promising framework to elicit emotions in an interactive set-up. But the studies reviewed above present several caveats. For example, in some games the interaction was limited to one or two iterations in each round with each subsequent round occurring with a different person (de Quervain et al., 2004; Sanfey et al., 2003). This issue has been the subject of criticism towards behavioral economics paradigms since ecologically valid interactions involve more than one or two iterations (Engemann et al., 2012). Nevertheless, others have defended this approach claiming that 
repeated iterations may still be supported by formal game-theory models (Gariépy et al., 2013). In other games described above participants consistently played with the same person across numerous iterations (Kahn et al, 2002; Dvash et al 2010). Although a more general criticism to such games may be their excessive emphasis on decision related processes and material payoffs, which are not a necessary part of real-life social encounters (Engemann et al, 2012). On the other hand such decisions provide objective behavioral measures that may be compared to other measures such as subjective reports. Notwithstanding, in all cases, even in studies from a more socially oriented perspective such as Cyberball (Eisenberg et al, 2003), artificially computerized paradigms constrained the interaction itself, which was based on simple button presses or visual information to convey decision actions and consequences, lacking real-life authenticity.

In one of the first studies to clearly use an interpersonal situation within the fMRI setting to evoke an emotional experience, specifically anger, participants were asked to solve difficult anagrams and say out loud through a microphone the correct answer or "no answer" if they did not know the answer (Denson et al., 2009). Anger was induced by the experimenter who interrupted participants twice, requesting them to speak louder, and on a third time stated in a rude and condescending tone of voice "Look, this is the third time I have had to say this! Can't you follow instructions?". Two-minute scans before the anagram task and immediately after the provoking criticism were compared and increased activity in the dACC was found, which positively correlated with self-reported anger. However participants could not respond to the provocations and brain activity was not measured during the actual induction of anger but only before and after. A step forward has recently been made in a study on the neural pathways of embarrassment (MüllerPinzler et al., 2015), which used the approach of social immersion (Krach et al., 2013). Such an approach suggests that real interactions are not necessary, rather the mental representation of oneself in regards to others. This approach in fact reflects many of the studies described above, such as on social exclusion, decision-making games and the study on envy and schadenfreude. Using clever set-ups, a situation is created at the beginning of experimentation in which a representation of 
oneself relative to others is constructed using a compelling cover story and subsequently no or only limited interaction is required while brain activity is actually being measured. Müller-Pinzler and colleagues (2015) created a substantial person-group interaction during which each participant interacted with three confederates for almost an hour before entering the MRI scanner to estimate the sizes, weights and quantities of various objects. The confederates supposedly performed the same task simultaneously outside the scanner, but in half of the cases served as an "audience" to participants' performance. Estimation accuracy and publicity of performance were manipulated revealing activations in dorsal aI and in mentalizing regions respectively, both of which functionally coupled with the ventral aI and amygdala specifically during embarrassing public failures. Although there wasn't a specific focus on the dynamic nature of embarrassment, a trial-by-trial analysis positively linked insula activity with sympathetic arousal as measured by pupil dilation. Indeed many of the above mentioned studies did not address the dynamic nature of the subjective experience being studied but could potentially address it using various methodological approaches such as trial-by-trial or functional connectivity analyses. Nevertheless, social immersion makes an assumption that portrays the above mentioned debate between enactivisim and individualism - is the mental representation of oneself in regards to others enough? This might be the case for embarrassment in which the experience of the emotion is dependent on the exposure to public attention, but this may not provide an adequate substitute for emotions such as anger elicited during dynamic, response contingent interactions (Gilam \& Hendler, 2015).

We recently combined the benefits of experimental games as a context to induce emotions with specific features of social interactions to study genuine interpersonal anger (Gilam et al., 2015). We utilized the UG as a context of interpersonal conflict over financial resources to reveal the neural substrates of a beneficial outcome to such a conflict, based on the premise that this relationship would be mediated by the emotional experience. The UG was modified such that participants repeatedly played the responder in 10 rounds with the same proposer. After each round participants in the scanner verbally negotiated for 30 seconds with the proposer in the control room, 
who was in fact a professional actor instructed to further induce anger using scripted improvisations. These on-line negotiations were reminiscent of bazaar-like bargaining involving violation of norms of conduct, personal insults and trash-talk. In validation of this manipulation we found that anger was indeed at the core of the emotional experience of participants. Our main findings suggested that through-out the game, the vmPFC played a role in modulating the subjective experience of anger en route to increased monetary gain, by possibly attenuating LC activity and associated arousal as measured by skin-conductance. Furthermore, during the more angering moments of the game, the neural coupling between dorsal posterior Insula and medial thalamus, both of which having a role in interoceptive processing, similarly contributed to increased gain by influencing the emotional experience. In line with the dynamic escalation property of anger, we also showed that subjective ratings of anger increased throughout the game and that high-gain participants had a similar increase in vmPFC activity as the game evolved. We suggested that the LC finding was related to our ecological interactive induction of anger since it was not previously reported in UG or anger studies even though previous findings relate this region's functionality with propagating aggressive behaviors (Haden and Scarpa, 2007; Haller et al., 1997). However we did not compare results to a standard UG as control. Moreover, although participants behaved and negotiated spontaneously, the putative proposer was instructed to interact with a clear goal to induce anger and thus had less "degrees of freedom". Also, there was a verbal interaction but participants and proposers did not see each other while interacting. Future studies should consider all the above mentioned limitations in order to further tweak experimental paradigms and bring us closer to "closing the loop" on social interactions in affective neuroscience.

\section{$\underline{\text { 6. Concluding remarks }}$}

We emphasize the importance of investigating complex phenomena within their naturalistic environment, and support the shift of neuroscience from an "isolated" to an "interacting" brainmode. As Cacioppo and Bernston wrote in their inception of the field of social neuroscience (1992, 
p. 1020): "the brain does not exist in isolation but rather is a fundamental but interacting component of a developing or aging individual who is a mere actor in the larger theater of life". Resonating with Goffman's work (1959), this theatre is social by nature. There is no doubt that neuroscientific knowledge increased invaluably and will continue to do so by investigating brain function using highly controlled experimental stimuli such as pictures of scenes or faces. Nevertheless, there seems to be a qualitative gap between common paradigms used in neuroimaging to induce emotional experiences and how emotions are actually experienced in the real world. We argue that people themselves play a critical role as instigators and proliferators of emotional episodes in one another. Therefore, from an experimental perspective, it is clear how this gap reflects different levels of ecological validity and generalizability. But from a theoretical point of view, it is yet unclear whether this gap would reflect different processing levels, or different patterns of neural activity and connectivity, or whether known neural-networks would be replicated. It seems implausible that "new" brain regions or networks would emerge from studying emotions during social interactions and one must remember that our knowledge of brain functionality is not solely derived from neuroimaging experiments. Yet the current evidence, limited as it may be, suggests that such an endeavor may implicate brain regions important for emotional experiences who aren't typically observed in less realistic paradigms and highlights interactions between brain regions involved in mentalizing, interoception and in emotional reactivity (Gilam et al, 2015; Müller-Pinzler et al., 2015).

In this review we demonstrated several possibilities for how social interactions may influence emotional experiences and conceptualized social emotions very broadly as both influenced by social context as well as possibly emerging from within social interactions. Further studies are clearly required to advance our understanding of whether and how social interactions may influence neural processing of emotional experiences and expressions and whether this would continue to support a brain organization based on domain-general processing. We believe that such an endeavor may also hold implications for various psychopathological conditions with apparent emotional and social 
abnormalities such as anxiety disorders, autism and schizophrenia (Gilam et al., Under review; Müller-Pinzler et al., 2016; Schilbach, 2016). To conclude, from either an experimental or a theoretical perspective, we maintain, paraphrasing James' opening citation above, that just as an artificially imitated sneeze lacks something of reality, so the attempt to imitate an emotion in the absence of social interactions is apt to be rather hollow.

\section{Acknowledgments:}

The authors thank the anonymous reviewers for their insightful and constructive comments that helped improve the manuscript. Additional thanks to A. Solski for copy editing and to the Sagol Network for Neuroscience. This work was supported by the University of Chicago's Arete Initiative - A New Science of Virtues Program (39174-07); the U.S. Department of Defense award (W81XWH-11-2-0008); and the I-CORE Program of the Planning and Budgeting Committee (51/11). The authors declare no competing financial interests. 


\section{References:}

Adolphs, R., 2009. The Social Brain: Neural Basis of Social Knowledge. Annu. Rev. Psychol. 60, 693-716. doi:10.1146/annurev.psych.60.110707.163514

Adolphs, R., 2003. Cognitive neuroscience of human social behaviour. Nat. Rev. Neurosci. 4, 165-178. doi:10.1038/nrn1056

Assaf, M., Kahn, I., Pearlson, G.D., Johnson, M.R., Yeshurun, Y., Calhoun, V.D., Hendler, T., 2009. Brain Activity Dissociates Mentalization from Motivation During an Interpersonal Competitive Game. Brain Imaging Behav. 3, 24-37. doi:10.1007/s11682-008-9047-y

Averill, J.R., 2012. The Future of Social Constructionism: Introduction to a Special Section of Emotion Review. Emot. Rev. 4, 215-220. doi:10.1177/1754073912439811

Babiloni, F., Astolfi, L., 2012. Social neuroscience and hyperscanning techniques: Past, present and future. Neurosci. Biobehav. Rev. doi:10.1016/j.neubiorev.2012.07.006

Barrett, L.F., 2009. Variety is the spice of life: A psychological construction approach to understanding variability in emotion. Cogn. Emot. 23, 1284-1306. doi:10.1080/02699930902985894

Barrett, L.F., Satpute, A.B., 2013. Large-scale brain networks in affective and social neuroscience: towards an integrative functional architecture of the brain. Curr. Opin. Neurobiol., Social and emotional neuroscience 23, 361-372. doi:10.1016/j.conb.2012.12.012

Batson, C.D., 2009. These things called empathy: Eight related but distinct phenomena, in: Decety, J., Ickes, W. (Eds.), The Social Neuroscience of Empathy, Social Neuroscience. MIT Press, Cambridge, MA, US, pp. 3-15.

Becchio, C., Sartori, L., Castiello, U., 2010. Toward You The Social Side of Actions. Curr. Dir. Psychol. Sci. 19, 183-188. doi:10.1177/0963721410370131

Bohil, C.J., Alicea, B., Biocca, F.A., 2011. Virtual reality in neuroscience research and therapy. Nat. Rev. Neurosci. 12, 752-762. doi:10.1038/nrn3122

Bradley, M.M., Lang, P.J., 2007. The International Affective Picture System (IAPS) in the study of emotion and attention, in: Coan, J.A., Allen, J.J.B. (Eds.), Handbook of Emotion Elicitation and Assessment, Series in Affective Science. Oxford University Press, New York, NY, US, pp. 29-46.

Bressler, S.L., Menon, V., 2010. Large-scale brain networks in cognition: emerging methods and principles. Trends Cogn. Sci. 14, 277-290. doi:10.1016/j.tics.2010.04.004

Britton, J.C., Phan, K.L., Taylor, S.F., Welsh, R.C., Berridge, K.C., Liberzon, I., 2006. Neural correlates of social and nonsocial emotions: An fMRI study. Neurolmage 31, 397-409. doi:10.1016/j.neuroimage.2005.11.027

Brothers, L., 1990. The social brain: a project for integrating primate behavior and neurophysiology in a new domain. Concepts Neurosci. 1, 27-51.

Brüne, M., Brüne-Cohrs, U., 2006. Theory of mind-evolution, ontogeny, brain mechanisms and psychopathology. Neurosci. Biobehav. Rev. 30, 437-455. doi:10.1016/j.neubiorev.2005.08.001

Buhle, J.T., Silvers, J.A., Wager, T.D., Lopez, R., Onyemekwu, C., Kober, H., Weber, J., Ochsner, K.N., 2014. Cognitive Reappraisal of Emotion: A Meta-Analysis of Human Neuroimaging Studies. Cereb. Cortex 24, 2981-2990. doi:10.1093/cercor/bht154

Burnett, S., Bird, G., Moll, J., Frith, C., Blakemore, S.-J., 2009. Development during adolescence of the neural processing of social emotion. J. Cogn. Neurosci. 21, 1736-1750. doi:10.1162/jocn.2009.21121

Byrne, R., Whiten, A., 1989. Machiavellian Intelligence : Social Expertise and the Evolution of Intellect in Monkeys, Apes, and Humans (Oxford Science Publications). \{Oxford University Press, USA\}.

Cacioppo, J.T., Berntson, G.G., 1992. Social psychological contributions to the decade of the brain: Doctrine of multilevel analysis. Am. Psychol. 47, 1019-1028. doi:10.1037/0003-066X.47.8.1019

Cacioppo, J.T., Cacioppo, S., Cole, S.W., 2013. Social Neuroscience and Social Genomics: The Emergence of Multi-Level Integrative Analyses. Int. J. Psychol. Res. 6, 1-6.

Camerer, C., 2003. Behavioral Game Theory. Russell Sage Foundation, New York.

Corbetta, M., Patel, G., Shulman, G.L., 2008. The Reorienting System of the Human Brain: From Environment to Theory of Mind. Neuron 58, 306-324. doi:10.1016/j.neuron.2008.04.017

Cunningham, W.A., 2013. Introduction to Special Section: Psychological Constructivism. Emot. Rev. 5, 333334. doi:10.1177/1754073913489786

Damasio, A., 2010. Self comes to mind: Constructing the conscious brain. Pantheon Books, New York, NY. 
Damasio, A.R., Grabowski, T.J., Bechara, A., Damasio, H., Ponto, L.L., Parvizi, J., Hichwa, R.D., 2000.

Subcortical and cortical brain activity during the feeling of self-generated emotions. Nat. Neurosci.

3, 1049-1056. doi:10.1038/79871

Deco, G., Corbetta, M., 2011. The Dynamical Balance of the Brain at Rest. The Neuroscientist 17, 107-123. doi:10.1177/1073858409354384

De Jaegher, H., Di Paolo, E., Adolphs, R., 2016. What does the interactive brain hypothesis mean for social neuroscience? A dialogue. Philos. Trans. R. Soc. B Biol. Sci. 371, 20150379. doi:10.1098/rstb.2015.0379

De Jaegher, H., Di Paolo, E., Gallagher, S., 2010. Can social interaction constitute social cognition? Trends Cogn. Sci. 14, 441-447. doi:10.1016/j.tics.2010.06.009

Denson, T.F., Pedersen, W.C., Ronquillo, J., Nandy, A.S., 2009. The Angry Brain: Neural Correlates of Anger, Angry Rumination, and Aggressive Personality. J. Cogn. Neurosci. 21, 734-744. doi:10.1162/jocn.2009.21051

de Quervain, D.J.-F. de, Fischbacher, U., Treyer, V., Schellhammer, M., Schnyder, U., Buck, A., Fehr, E., 2004. The Neural Basis of Altruistic Punishment. Science 305, 1254-1258. doi:10.1126/science.1100735

Di Paolo, E., De Jaegher, H., 2012. The interactive brain hypothesis. Front. Hum. Neurosci. 6. doi:10.3389/fnhum.2012.00163

Dunbar, R.I.M., 2003. The Social Brain: Mind, Language, and Society in Evolutionary Perspective. Annu. Rev. Anthropol. 32, 163-181. doi:10.2307/25064825

Dunbar, R.I.M., 1998. The social brain hypothesis. Evol. Anthropol. Issues News Rev. 6, 178-190. doi:10.1002/(SICI)1520-6505(1998)6:5<178::AID-EVAN5>3.0.CO;2-8

Dvash, J., Gilam, G., Ben-Ze'ev, A., Hendler, T., Shamay-Tsoory, S.G., 2010. The envious brain: The neural basis of social comparison. Hum. Brain Mapp. 31, 1741-1750. doi:10.1002/hbm.20972

Eilan, N., 2005. Joint Attention: Communication and Other Minds : Issues in Philosophy and Psychology. Clarendon Press; New York.

Eisenberger, N.I., Lieberman, M.D., Williams, K.D., 2003. Does Rejection Hurt? An fMRI Study of Social Exclusion. Science 302, 290-292. doi:10.1126/science.1089134

Eisenberg, N., 2000. Emotion, Regulation, and Moral Development. Annu. Rev. Psychol. 51, 665-697. doi:10.1146/annurev.psych.51.1.665

Ekman, P., Cordaro, D., 2011. What is Meant by Calling Emotions Basic. Emot. Rev. 3, 364-370. doi:10.1177/1754073911410740

Engemann, D.A., Bzdok, D., Eickhoff, S.B., Vogeley, K., Schilbach, L., 2012. Games people play--toward an enactive view of cooperation in social neuroscience. Front. Hum. Neurosci. 6. doi:10.3389/fnhum.2012.00148

Fischer, A.H., Kleef, G.A. van, 2010. Where Have All the People Gone? A Plea for Including Social Interaction in Emotion Research. Emot. Rev. 2, 208-211. doi:10.1177/1754073910361980

Fiske, S.T., C, J., Glick, P., Xu, J., 2002. A model of (often mixed) stereotype content: Competence and warmth respectively follow from perceived status and competition. J. Pers. Soc. Psychol. 82, 878902. doi:10.1037/0022-3514.82.6.878

Frewen, P.A., Dozois, D.J.A., Neufeld, R.W.J., Densmore, M., Stevens, T.K., Lanius, R.A., 2011. Neuroimaging social emotional processing in women: fMRI study of script-driven imagery. Soc. Cogn. Affect. Neurosci. 6, 375-392. doi:10.1093/scan/nsq047

Frijda, N.H., 2009. Emotions, individual differences and time course: Reflections. Cogn. Emot. 23, 14441461. doi:10.1080/02699930903093276

Frijda, N.H., 1986. The Emotions. Cambridge University Press.

Fusar-Poli, P., Placentino, A., Carletti, F., Landi, P., Allen, P., Surguladze, S., Benedetti, F., Abbamonte, M., Gasparotti, R., Barale, F., Perez, J., McGuire, P., Politi, P., 2009. Functional atlas of emotional faces processing: a voxel-based meta-analysis of 105 functional magnetic resonance imaging studies. J. Psychiatry Neurosci. JPN 34, 418-432.

Gallotti, M., Frith, C.D., 2013. Social cognition in the we-mode. Trends Cogn. Sci. 17, 160-165. doi:10.1016/j.tics.2013.02.002

Gariépy, J.-F., Chang, S.W.C., Platt, M.L., 2013. Brain games: Toward a neuroecology of social behavior. Behav. Brain Sci. 36, 424-425. doi:10.1017/S0140525X12001938 
Gendron, M., Barrett, L.F., 2009. Reconstructing the Past: A Century of Ideas About Emotion in Psychology. Emot. Rev. 1, 316-339. doi:10.1177/1754073909338877

Gilam, G., Hendler, T., 2015. Deconstructing Anger in the Human Brain, in: Wöhr, M., Krach, S. (Eds.), Social Behavior from Rodents to Humans: Neural Foundations and Clinical Implications, Current Topics in Behavioral Neurosciences. Springer Berlin Heidelberg, pp. 1-17.

Gilam, G., Lin, T., Fruchter, E., Hendler, T., Under review. Neural indicators of interpersonal anger as cause and consequence of chronic-stress related PTSD-symptoms.

Gilam, G., Lin, T., Raz, G., Azrielant, S., Fruchter, E., Ariely, D., Hendler, T., 2015. Neural substrates underlying the tendency to accept anger-infused ultimatum offers during dynamic social interactions. Neurolmage 120, 400-411. doi:10.1016/j.neuroimage.2015.07.003

Goffman, E., 1959. The Presentation of Self in Everyday Life, 1st ed. Anchor.

Gruberger, M., Simon, E.B., Levkovitz, Y., Zangen, A., Hendler, T., 2011. Towards a neuroscience of mindwandering. Front. Hum. Neurosci. 5, 56.

Güth, W., Schmittberger, R., Schwarze, B., 1982. An experimental analysis of ultimatum bargaining. J. Econ. Behav. Organ. 3, 367-388. doi:10.1016/0167-2681(82)90011-7

Haden, S.C., Scarpa, A., 2007. The noradrenergic system and its involvement in aggressive behaviors. Aggress. Violent Behav. 12, 1-15. doi:10.1016/j.avb.2006.01.012

Haller, J., Makara, G.B., Kruk, M.R., 1997. Catecholaminergic involvement in the control of aggression: hormones, the peripheral sympathetic, and central noradrenergic systems. Neurosci. Biobehav. Rev. 22, 85-97. doi:10.1016/S0149-7634(97)00023-7

Hareli, S., Parkinson, B., 2008. What's Social About Social Emotions? J. Theory Soc. Behav. 38, 131-156. doi:10.1111/j.1468-5914.2008.00363.x

Hari, R., Henriksson, L., Malinen, S., Parkkonen, L., 2015. Centrality of Social Interaction in Human Brain Function. Neuron 88, 181-193. doi:10.1016/j.neuron.2015.09.022

Hari, R., Kujala, M.V., 2009. Brain Basis of Human Social Interaction: From Concepts to Brain Imaging. Physiol. Rev. 89, 453-479. doi:10.1152/physrev.00041.2007

Hari, R., Sams, M., Nummenmaa, L., 2016. Attending to and neglecting people: bridging neuroscience, psychology and sociology. Philos. Trans. R. Soc. B Biol. Sci. 371, 20150365. doi:10.1098/rstb.2015.0365

Harris, L.T., Fiske, S.T., 2006. Social groups that elicit disgust are differentially processed in mPFC. Soc. Cogn. Affect. Neurosci. doi:10.1093/scan/nsI037

Hasson, U., Honey, C.J., 2012. Future trends in Neuroimaging: Neural processes as expressed within real-life contexts. Neurolmage 62, 1272-1278. doi:10.1016/j.neuroimage.2012.02.004

Hatfield, E., Cacioppo, J.T., Rapson, R.L., 1994. Emotional contagion, Studies in emotion and social interaction. Editions de la Maison des Sciences de l'Homme, Paris, France.

He, B., Coleman, T., Genin, G.M., Glover, G., Hu, X., Johnson, N., Liu, T., Makeig, S., Sajda, P., Ye, K., 2013. Grand challenges in mapping the human brain: NSF workshop report. IEEE Trans Biomed Eng. 60, 2983-2992.

James, W., 1884. What is an Emotion? Mind 9, 188-205.

Kahn, I., Yeshurun, Y., Rotshtein, P., Fried, I., Ben-Bashat, D., Hendler, T., 2002. The Role of the Amygdala in Signaling Prospective Outcome of Choice. Neuron 33, 983-994. doi:10.1016/S0896-6273(02)006268

Kober, H., Barrett, L.F., Joseph, J., Bliss-Moreau, E., Lindquist, K., Wager, T.D., 2008. Functional grouping and cortical-subcortical interactions in emotion: A meta-analysis of neuroimaging studies. Neurolmage 42, 998-1031. doi:10.1016/j.neuroimage.2008.03.059

Krach, S., Cohrs, J.C., de Echeverría Loebell, N.C., Kircher, T., Sommer, J., Jansen, A., Paulus, F.M., 2011. Your Flaws Are My Pain: Linking Empathy To Vicarious Embarrassment. PLoS ONE 6, e18675. doi:10.1371/journal.pone.0018675

Krach, S., Müller-Pinzler, L., Westermann, S., Paulus, F.M., 2013. Advancing the neuroscience of social emotions with social immersion. Behav. Brain Sci. 36, 427-428. doi:10.1017/S0140525X12001951

Lamm, C., Singer, T., 2010. The role of anterior insular cortex in social emotions. Brain Struct. Funct. 214, 579-591. doi:10.1007/s00429-010-0251-3

LeDoux, J.E., 1992. Emotion and the amygdala, in: The Amygdala: Neurobiological Aspects of Emotion, Memory, and Mental Dysfunction. Wiley-Liss, New York, NY, US, pp. 339-351. 
Lench, H.C., Flores, S.A., Bench, S.W., 2011. Discrete emotions predict changes in cognition, judgment, experience, behavior, and physiology: A meta-analysis of experimental emotion elicitations. Psychol. Bull. 137, 834-855. doi:10.1037/a0024244

Lerner, J.S., Li, Y., Valdesolo, P., Kassam, K.S., 2015. Emotion and Decision Making. Annu. Rev. Psychol. 66, 799-823. doi:10.1146/annurev-psych-010213-115043

Lewis, M., 1995. Embarrassment: The emotion of self-exposure and evaluation, in: Tangney, J.P., Fischer, K.W. (Eds.), Self-Conscious Emotions: The Psychology of Shame, Guilt, Embarrassment, and Pride. Guilford Press, New York, NY, US, pp. 198-218.

Lewis, M., Sullivan, M.W., Stanger, C., Weiss, M., 1989. Self Development and Self-Conscious Emotions. Child Dev. 60, 146. doi:10.2307/1131080

Lindquist, K.A., Barrett, L.F., 2012. A functional architecture of the human brain: emerging insights from the science of emotion. Trends Cogn. Sci. 16, 533-540. doi:10.1016/j.tics.2012.09.005

Lindquist, K.A., Wager, T.D., Kober, H., Bliss-Moreau, E., Barrett, L.F., 2012. The brain basis of emotion: A meta-analytic review. Behav. Brain Sci. 35, 121-143. doi:10.1017/S0140525X11000446

Markus, H.R., Kitayama, S., 1991. Culture and the self: Implications for cognition, emotion, and motivation. Psychol. Rev. 98, 224-253. doi:10.1037/0033-295X.98.2.224

Mars, R.B., Neubert, F.-X., Noonan, M.P., Sallet, J., Toni, I., Rushworth, M.F.S., 2012. On the relationship between the "default mode network" and the "social brain." Front. Hum. Neurosci. 6. doi:10.3389/fnhum.2012.00189

Mead, G.H., 1934. Mind, self and society. Chicago University of Chicago Press.

Miller, E.K., Cohen, J.D., 2001. An Integrative Theory of Prefrontal Cortex Function. Annu. Rev. Neurosci. 24, 167-202. doi:10.1146/annurev.neuro.24.1.167

Miller, R.S., 1995. Embarrassment and social behavior, in: Tangney, J.P., Fischer, K.W. (Eds.), Self-Conscious Emotions: The Psychology of Shame, Guilt, Embarrassment, and Pride. Guilford Press, New York, NY, US, pp. 322-339.

Montague, P.R., Berns, G.S., Cohen, J.D., McClure, S.M., Pagnoni, G., Dhamala, M., Wiest, M.C., Karpov, I., King, R.D., Apple, N., Fisher, R.E., 2002. Hyperscanning: Simultaneous fMRI during Linked Social Interactions. Neurolmage 16, 1159-1164. doi:10.1006/nimg.2002.1150

Moors, A., Ellsworth, P.C., Scherer, K.R., Frijda, N.H., 2013. Appraisal Theories of Emotion: State of the Art and Future Development. Emot. Rev. 5, 119-124. doi:10.1177/1754073912468165

Müller-Pinzler, L., Gazzola, V., Keysers, C., Sommer, J., Jansen, A., Frässle, S., Einhäuser, W., Paulus, F.M., Krach, S., 2015. Neural pathways of embarrassment and their modulation by social anxiety. Neurolmage 119, 252-261. doi:10.1016/j.neuroimage.2015.06.036

Müller-Pinzler, L., Krach, S., Krämer, U.M., Paulus, F.M., 2016. The Social Neuroscience of Interpersonal Emotions, in: Current Topics in Behavioral Neurosciences. Springer Berlin Heidelberg, pp. 1-16.

Panksepp, J., 1998. Affective Neuroscience: The Foundations of Human and Animal Emotions. Oxford University Press.

Parrott, W.G., 2001. Emotions in social psychology: Essential readings. Psychology Press.

Pfeiffer, U.J., Timmermans, B., Vogeley, K., Frith, C.D., Schilbach, L., 2013. Towards a neuroscience of social interaction. Front. Hum. Neurosci. 7. doi:10.3389/fnhum.2013.00022

Pillutla, M.M., Murnighan, J.K., 1996. Unfairness, anger, and spite: Emotional rejections of ultimatum offers. Organ. Behav. Hum. Decis. Process. 68, 208-224. doi:10.1006/obhd.1996.0100

Przyrembel, M., Smallwood, J., Pauen, M., Singer, T., 2012. Illuminating the dark matter of social neuroscience: Considering the problem of social interaction from philosophical, psychological, and neuroscientific perspectives. Front. Hum. Neurosci. 6. doi:10.3389/fnhum.2012.00190

Raichle, M.E., 2010. Two views of brain function. Trends Cogn. Sci. 14, 180-190. doi:10.1016/j.tics.2010.01.008

Ratner, C., 2000. A Cultural-Psychological Analysis of Emotions. Cult. Psychol. 6, 5-39. doi:10.1177/1354067X0061001

Raz, G., Jacob, Y., Gonen, T., Winetraub, Y., Flash, T., Soreq, E., Hendler, T., 2014. Cry for her or cry with her: context-dependent dissociation of two modes of cinematic empathy reflected in network cohesion dynamics. Soc. Cogn. Affect. Neurosci. 9, 30-38. doi:10.1093/scan/nst052 
Raz, G., Winetraub, Y., Jacob, Y., Kinreich, S., Maron-Katz, A., Shaham, G., Podlipsky, I., Gilam, G., Soreq, E., Hendler, T., 2012. Portraying emotions at their unfolding: A multilayered approach for probing dynamics of neural networks. Neurolmage 60, 1448-1461. doi:10.1016/j.neuroimage.2011.12.084

Risko, E.F., Laidlaw, K.E.W., Freeth, M., Foulsham, T., Kingstone, A., 2012. Social attention with real versus reel stimuli: toward an empirical approach to concerns about ecological validity. Front. Hum. Neurosci. 6. doi:10.3389/fnhum.2012.00143

Rogers, K.B., Schröder, T., Scheve, C. von, 2014. Dissecting the Sociality of Emotion: A Multilevel Approach. Emot. Rev. 6, 124-133. doi:10.1177/1754073913503383

Russell, J.A., 2012. Introduction to Special Section: On Defining Emotion. Emot. Rev. 4, 337-337. doi:10.1177/1754073912445857

Russell, J.A., Barrett, L.F., 1999. Core affect, prototypical emotional episodes, and other things called emotion: Dissecting the elephant. J. Pers. Soc. Psychol. 76, 805-819. doi:10.1037/00223514.76.5.805

Russell, J.A., Rosenberg, E.L., Lewis, M.D., 2011. Introduction to a Special Section on Basic Emotion Theory. Emot. Rev. 3, 363-363. doi:10.1177/1754073911411606

Saito, D.N., Tanabe, H.C., Izuma, K., Hayashi, M.J., Morito, Y., Komeda, H., Uchiyama, H., Kosaka, H., Okazawa, H., Fujibayashi, Y., Sadato, N., 2010. "Stay Tuned": Inter-Individual Neural Synchronization During Mutual Gaze and Joint Attention. Front. Integr. Neurosci. 4. doi:10.3389/fnint.2010.00127

Sanfey, A.G., 2007. Social Decision-Making: Insights from Game Theory and Neuroscience. Science 318, 598-602. doi:10.1126/science.1142996

Sanfey, A.G., Rilling, J.K., Aronson, J.A., Nystrom, L.E., Cohen, J.D., 2003. The Neural Basis of Economic Decision-Making in the Ultimatum Game. Science 300, 1755-1758. doi:10.1126/science.1082976

Scherer, K.R., Tannenbaum, P.H., 1986. Emotional experiences in everyday life: A survey approach. Motiv. Emot. 10, 295-314. doi:10.1007/BF00992106

Scherer, K.R., Wranik, T., Sangsue, J., Tran, V., Scherer, U., 2004. Emotions in everyday life: probability of occurrence, risk factors, appraisal and reaction patterns. Soc. Sci. Inf. 43, 499-570. doi:10.1177/0539018404047701

Schilbach, L., 2016. Towards a second-person neuropsychiatry. Phil Trans R Soc B 371, 20150081. doi:10.1098/rstb.2015.0081

Schilbach, L., 2015. Eye to eye, face to face and brain to brain: novel approaches to study the behavioral dynamics and neural mechanisms of social interactions. Curr. Opin. Behav. Sci., Social behavior 3 , 130-135. doi:10.1016/j.cobeha.2015.03.006

Schilbach, L., Bzdok, D., Timmermans, B., Fox, P.T., Laird, A.R., Vogeley, K., Eickhoff, S.B., 2012. Introspective Minds: Using ALE Meta-Analyses to Study Commonalities in the Neural Correlates of Emotional Processing, Social \& Unconstrained Cognition. PLoS ONE 7, e30920. doi:10.1371/journal.pone.0030920

Schilbach, L., Eickhoff, S.B., Rotarska-Jagiela, A., Fink, G.R., Vogeley, K., 2008. Minds at rest? Social cognition as the default mode of cognizing and its putative relationship to the "default system" of the brain. Conscious. Cogn. 17, 457-467. doi:10.1016/j.concog.2008.03.013

Schilbach, L., Timmermans, B., Reddy, V., Costall, A., Bente, G., Schlicht, T., Vogeley, K., 2013. Toward a second-person neuroscience. Behav. Brain Sci. 36, 393-414. doi:10.1017/S0140525X12000660

Schilbach, L., Wohlschlaeger, A.M., Kraemer, N.C., Newen, A., Shah, N.J., Fink, G.R., Vogeley, K., 2006. Being with virtual others: Neural correlates of social interaction. Neuropsychologia 44, 718-730. doi:10.1016/j.neuropsychologia.2005.07.017

Schonberg, T., Fox, C.R., Poldrack, R.A., 2011. Mind the gap: bridging economic and naturalistic risk-taking with cognitive neuroscience. Trends Cogn. Sci. 15, 11-19. doi:10.1016/j.tics.2010.10.002

Singer, T., Critchley, H.D., Preuschoff, K., 2009. A common role of insula in feelings, empathy and uncertainty. Trends Cogn. Sci. 13, 334-340. doi:10.1016/j.tics.2009.05.001

Singer, T., Seymour, B., O'Doherty, J., Kaube, H., Dolan, R.J., Frith, C.D., 2004. Empathy for Pain Involves the Affective but not Sensory Components of Pain. Science 303, 1157-1162. doi:10.1126/science.1093535 
Singer, T., Seymour, B., O’Doherty, J.P., Stephan, K.E., Dolan, R.J., Frith, C.D., 2006. Empathic neural responses are modulated by the perceived fairness of others. Nature 439, 466-469. doi:10.1038/nature04271

Srivastava, J., Espinoza, F., Fedorikhin, A., 2009. Coupling and decoupling of unfairness and anger in ultimatum bargaining. J. Behav. Decis. Mak. 22, 475-489. doi:10.1002/bdm.631

Tangney, J.P., Fischer, K.W. (Eds.), 1995. Self-conscious emotions: The psychology of shame, guilt, embarrassment, and pride. Guilford Press, New York, NY, US.

Tracy, J.L., Robins, R.W., 2004. Putting the Self Into Self-Conscious Emotions: A Theoretical Model. Psychol. Inq. 15, 103-125. doi:10.1207/s15327965pli1502_01

Wagner, U., N'Diaye, K., Ethofer, T., Vuilleumier, P., 2011. Guilt-Specific Processing in the Prefrontal Cortex. Cereb. Cortex bhr016. doi:10.1093/cercor/bhr016

Whiten, A., Byrne, R.W., 1997. Machiavellian Intelligence II: Extensions and Evaluations. Cambridge University Press.

Wilson-Mendenhall, C.D., Barrett, L.F., Barsalou, L.W., 2013. Neural Evidence That Human Emotions Share Core Affective Properties. Psychol. Sci. 24, 947-956. doi:10.1177/0956797612464242

Xiao, E., Houser, D., 2005. Emotion expression in human punishment behavior. Proc. Natl. Acad. Sci. U. S. A. 102, 7398-7401. doi:10.1073/pnas.0502399102

Yarkoni, T., Poldrack, R.A., Nichols, T.E., Van Essen, D.C., Wager, T.D., 2011. Large-scale automated synthesis of human functional neuroimaging data. Nat. Methods 8, 665-670. doi:10.1038/nmeth.1635

Zaki, J., Ochsner, K., 2009. The Need for a Cognitive Neuroscience of Naturalistic Social Cognition. Ann. N. Y. Acad. Sci. 1167, 16-30. doi:10.1111/j.1749-6632.2009.04601.x 


\section{Figure Captions:}

Table 1: Compatibility of induction methods and exemplar studies to features of social interaction

The table summarizes how various emotion induction methods, exemplars of interactive games and finally specific paradigms created to study specific emotions, comply $(\sqrt{ }=$ yes; $x=$ no; other $)$ with general features of emotions, as with specific features of social interactions. The general features include the level of experimental control that can be implemented using the paradigm, whether it relates to a specific emotion, whether the stimuli can be embedded within a social context, whether social immersion can be used in tandem with the emotional stimuli or paradigm and whether the paradigm enables to study the temporal dynamics of the emotional experience. The specific features of social interactions include the reciprocal influence between interacting partners and each partners' (at least one of them being the participant) range of responses. 
Figure 1: Social-emotional overlap in the human brain

Panel A illustrates NeuroSynth (http://www.neurosynth.org/) term-based forward inference metaanalytic maps for the terms social (green; 1000 studies) and emotional (red; 1340 studies). A forward inference map provides information about the likelihood of each voxel to activate if a study uses the term (i.e., $\mathrm{P}($ activation|term), at a false discovery rate of $1 \%)$, alluding to the importance of the voxel to that term. There were a total of 11406 studies on December $5^{\text {th }}, 2015$ - the date the maps were downloaded. The overlap between the social and emotional maps is illustrated in yellow. Marked regions include the amygdala, thalamus, caudate, middle temporal lobe, fusiform gyrus (FFG), inferior frontal gyrus (IFG), anterior insula (AI), medial prefrontal cortex (mPFC), anterior cingulate gyrus (ACC), supplementary motor cortex (SMA), posterior cingulate gyrus (PCC), precuneus, lateral prefrontal cortex (IPFC), and motor and parietal regions. The two left brain slices, the middle slices and the two right slices present sagittal, axial and coronal slices, respectively. The number above each slide refers to its MNI plane (x, y, z respectively). Panel B illustrates the same maps after removing 314 studies that were included in both terms thus presenting a mutually exclusive subset (social=686 studies; http://neurosynth.org/analyses/custom/122a315b-0c06-4c78/; emotional=1026 studies; http://neurosynth.org/analyses/custom/1559b18a-a7b0-443f/). The overlap was apparent in similar brain regions though to a lesser extent. Panel C illustrates the meta-analytic map of the 314 studies shared by both the social and emotional terms (http://neurosynth.org/analyses/custom/9c442c82-bdbd-4f83/). 


\section{Figures \& Tables:}

Table 1:

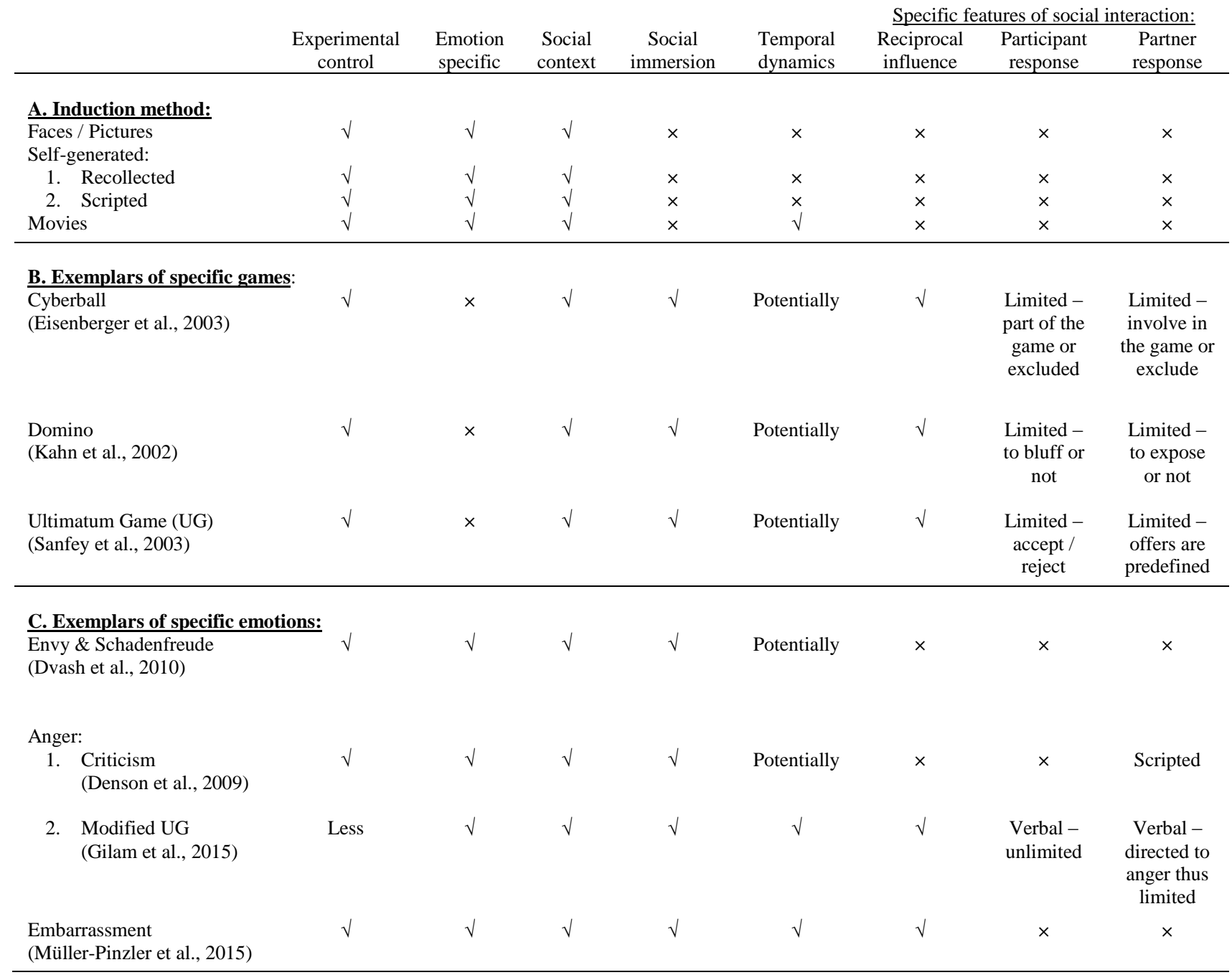


Figure 1:

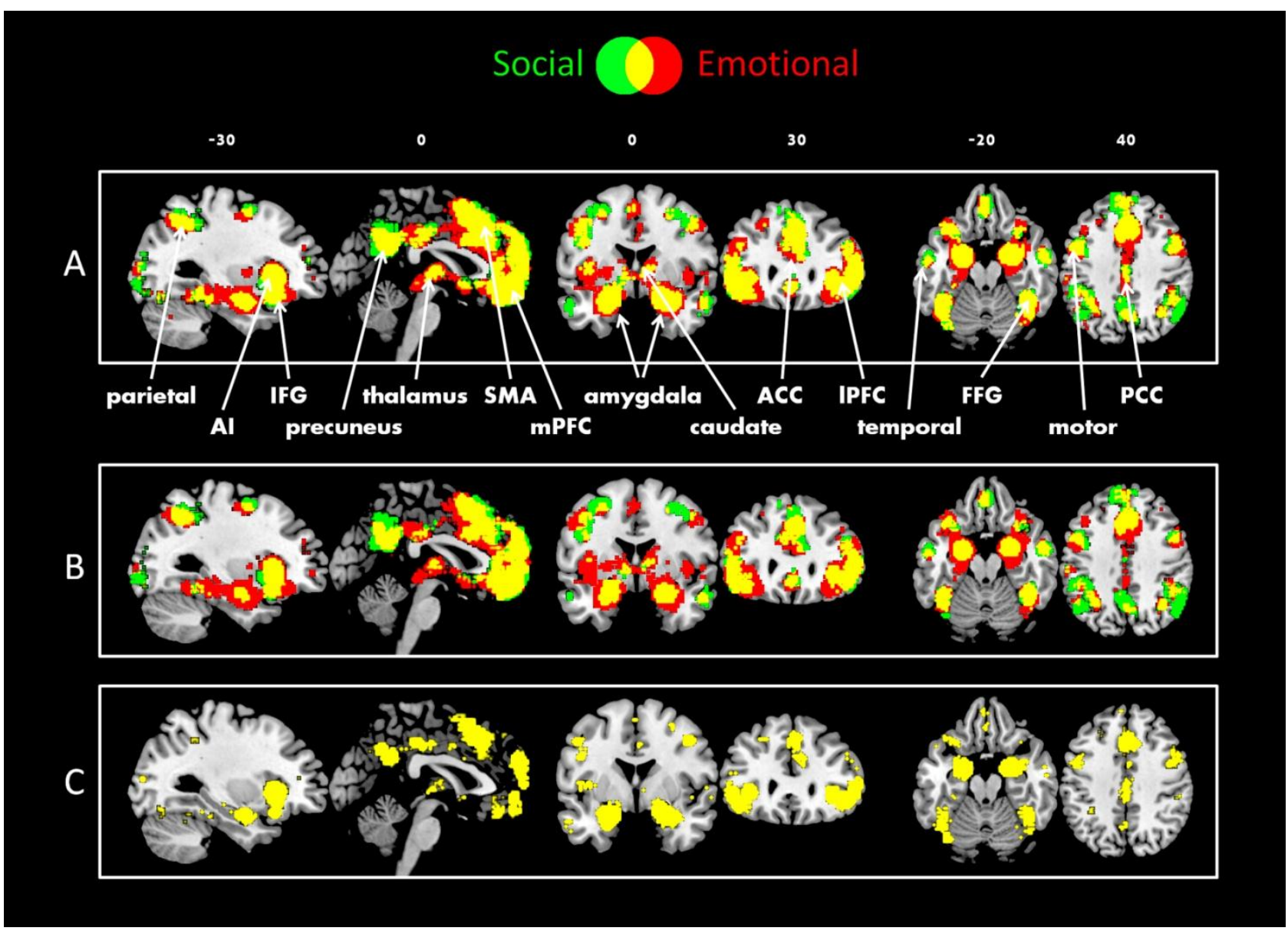

